\title{
PENETRATION OF A GLASS-FACED TRANSPARENT ELASTOMERIC RESIN BY A LEAD-ANTIMONY-CORED BULLET
}

\author{
P J Hazell $^{1 *}$, M R Edwards ${ }^{1}$, H Longstaff ${ }^{1}$ and J Erskine ${ }^{2}$ \\ ${ }^{1}$ Cranfield University, Defence College of Management and Technology, Shrivenham, Oxfordshire, \\ SN6 8LA, United Kingdom. \\ ${ }^{2}$ Hamilton Erskine Ltd, 17 Moss Road, Ballygowan, Co. Down, BT23 6JQ, Northern Ireland. \\ ${ }^{*}$ Corresponding author
}

\section{SUMMARY}

The penetration of the lead antimony-cored $7.62 \mathrm{~mm} \times 51 \mathrm{~mm}$ bullet into a glass-faced polyurethane elastomeric polymer resin has been studied. The resulting craters in the resin contained elongated bullet core material that had a significant amount of porosity. A simple linear viscoelastic model was applied to AUTODYN$2 \mathrm{D}$ to describe the behaviour of the resin and numerical results of the penetration mechanism and depth-of-penetration appeared to match experimental observations well. Analysis of the high-speed photography and a numerical model of this bullet penetrating a viscoelastic polymer showed that during the initial stages of penetration, the projectile is essentially turned inside-out. Furthermore, the shape of the cavity was defined by the elastic relaxation of the polymer that led to compression of the core material. A weight analysis of the penetrated materials showed that using a thicker tile of glass resulted in better ballistic performance.

Keywords: lead-antimony-cored bullet, penetration mechanisms, elastomeric resin, transparent armour, numerical modelling. 


\section{INTRODUCTION}

Armour systems usually consist of a hard disrupting face and some kind of absorbing element behind. The purpose of the disruptor is to induce fragmentation in the projectile or induce erosion thereby redirecting and dispersing the kinetic energy. The absorber on the other hand, acts to transfer the kinetic energy of the projectile to a lower form of energy - such as heat, through inelastic deformation (for example). A review of materials used for ballistic protection applications can be found in Edwards [1]

Typical commercially available transparent armour use laminates consisting of glass with interlayers of polyvinylbutyrate backed by a layer of polycarbonate. Individual materials that are used in these systems have been extensively studied under a wide variety of loading conditions by a number of researchers $[2,3,4,5,6]$. Understandably, most researchers opt for using a simple projectile design such as a sphere or rod. However, unlike ceramic-faced armours where there is a plethora of data dating back from the 1960s on penetration by high velocity rifle bullets (e.g. [1, $7,8,9,10,11,12])$, there is a paucity of data on the impact and penetration of glassfaced materials using these relatively complex projectiles.

Despite the advances in the manufacture of transparent ceramic materials such as Aluminium Oxynitride and Spinel the most commonly used disruptor-type material used in a transparent armour system is glass. Float-glass (for example) is a hard material but is very brittle. The high hardness of the glass elements (400-500HV) disrupts the projectile whilst the polymeric interlayer and boundary layers in a laminate armour system act to confine the fragmentation.

A candidate polymer material that can be incorporated into transparent armour designs is a thermosetting polyurethane resin known as a polyurethane replacement 
resin (PRR). This resin has advantageous properties for the manufacture of laminate armour systems. It is transparent and has also been shown to be a candidate for nanoparticle reception that provides the possibility of enhancing the strength of the material whilst maintaining good transparency [13]. It has a lower density than either glass or the polycarbonate. In contrast to polycarbonate which has a plastic elongation of $100-150 \%$, this resin is elastomeric with a typical elastic elongation of greater than $150 \%$. It possesses a coefficient of thermal expansion that is very similar to glass and can be moulded into any shape. It can also be cured in contact with the glass to provide strong adhesion.

The aim of this present work is to examine the penetration of a lead-antimonycored small-arms bullet $(7.62 \mathrm{~mm} \times 51 \mathrm{~mm}$ NATO Ball) into a glass-face backed by this elastomeric resin. In the target set-up we are using relatively large thicknesses of resin to examine the effect that this material has on a lead antimony projectile. Modelling approaches, using a simple linear viscoelastic model for the resin have been used to enhance our understanding of the early stages of penetration. To the best of our knowledge, this is the first time results of penetration of a soft-cored projectile into a glass-faced transparent elastomer have been presented.

\section{EXPERIMENTAL}

\section{Materials Used}

The targets were manufactured by Hamilton Erskine Ltd by casting the thermosetting polyurethane replacement resin (PRR) into transparent 6-mm thick polycarbonate surrounds. During this process the float glass facings of $6 \mathrm{~mm}, 8 \mathrm{~mm}$, or $10 \mathrm{~mm}$ thickness were chemically bonded to the resin as it cured. These targets were $100-\mathrm{mm}$ square and were at least $45 \%$ thicker than the maximum depth-of- 
penetration. Additional targets using 6-mm and 10 -mm thick glass were also tested where the resin had been cured into a $\varnothing 87-\mathrm{mm}$ plastic beer cup. The beer cups were $112 \mathrm{~mm}$ deep and tapered to a diameter of $68 \mathrm{~mm}$ over their depth. The glass used was float glass $\left(\mathrm{SiO}_{2}\right.$ 72.6, $\mathrm{Na}_{2} \mathrm{O}$ 13.0, $\mathrm{CaO}$ 8.4, $\mathrm{MgO}$ 4.0, $\mathrm{Al}_{2} \mathrm{O}_{3}, 1.0$ weight percent) manufactured by Pilkingtons; $\rho=2500 \mathrm{~kg} / \mathrm{m}^{3}$. A target without the glass-face was also tested.

The bullet used was a $7.62 \mathrm{~mm} \times 51 \mathrm{~mm}$ NATO Ball round. The lead antimony core was of composition (weight percent) Sb 10.2, $\mathrm{Cu} 0.16$, balance $\mathrm{Pb}$ with no other element greater than 0.05 weight percent. The core was enclosed in a gilding metal $(\mathrm{Cu}-10 \mathrm{Zn})$ jacket. The microstructure of the core was the expected eutectic mixture with small amounts of primary antimony. Key properties of the bullet are shown in Table 1; the geometry and key dimensions of the bullet are shown in Figure 1. Hardness measurements were carried out using an Indentec HWDM7 digital micro hardness machine.

The yaw characteristic of this projectile fired from our experimental set-up was measured by firing fifteen projectiles and imaging the yaw in the vertical and horizontal planes using a single Phantom 7 high-speed video camera and an angled mirror. The average maximum yaw recorded in the field-of-view (255 mm) was $1.8^{\circ}$ with a standard deviation of $0.7^{\circ}$.

Table 1: NEAR HERE

Figure 1: NEAR HERE 
The properties of the resin are summarised in Table 2. The density was measured using a Micrometrics AccuPyc 1330 gas pycnometer. Tensile properties were measured using an Instron universal testing machine and the longitudinal wave velocity was measured using a Panametrics $5 \mathrm{MHz}$ transducer using the pulse-echo method.

Table 2: NEAR HERE

\section{Experimental methods}

The bullets were fired from a proof barrel situated 10 metres from the front of the target. The average velocity of the bullet was $844 \mathrm{~m} / \mathrm{s}$ with a standard deviation of $10 \mathrm{~m} / \mathrm{s}$; bullet velocities were measured using a sky-screen system. A Phantom 7 high-speed video camera was used to measure the motion of the bullet through the target. Frame speeds of 80,000 frames -per-second were used with exposure times of $2 \mu \mathrm{s}$.

Optical microscopy was carried out on polished (and etched samples). Because of the low melting point of the lead-antimony alloy, specimens were mounted in a cold-setting polymer rather than the customary bakelite. Polishing was done using an automatic polishing machine and diamond paste (1 micron). Etching was carried out using an aqueous solution of ferric chloride for examination of the copper gilding metal and glacial acetic acid, concentrated nitric acid and glycerol for the lead-antimony. 


\section{NUMERICAL}

To provide insight into the penetration mechanisms a numerical model was developed in an explicit non-linear transient dynamic numerical code - AUTODYN2D. All simulations were done using axial symmetry.

Many of the values required for the constitutive models are currently unknown and therefore the penetration into a known elastomeric material (polyrubber) with a similar density to the PRR was simulated. This software is explained in detail elsewhere [14]. However in brief, this code solves the conservations laws of mass and momentum based on initial boundary conditions. The user is prompted for an equation of state that describes the pressure in terms of the internal energy and volume and a constitutive relationship that calculates the flow stress in terms of a number of material and application-dependent parameters including strain, strain-rate and temperature. Failure models can be introduced to describe the failure.

The behaviour of the lead antimony core was simulated using an elastic perfectly plastic criterion using a yield strength of $40 \mathrm{MPa}$. This was due to the low melting point of this material where strain hardening effects are assumed to be minimal. Hardness measurements of the lead antimony from the recovered projectiles embedded in the resin indicated that little or no strain-hardening had occurred which is consistent with this low melting point alloy. Strain-rate effects for this material were also assumed to be negligible. Thermal softening was introduced by adopting the approach used by Johnson and Cook [15] viz.

$$
\sigma=\sigma_{y}\left[1-\left(\frac{T-T_{r}}{T_{m}-T_{r}}\right)^{m}\right]
$$

where $T$ is the temperature, $T_{m}$ is the melting temperature, $T_{r}$ is the reference temperature ( $293 \mathrm{~K}), m$ is the thermal softening exponent, $\sigma_{y}$ is the yield strength of 
the material and $\sigma$ is the resulting flow stress due to thermal softening. Strain to failure values for this type of lead-alloy lie in the region of 15 -- $20 \%$ [16]

The gilding metal jacket was modelled assuming a flow stress of $575 \mathrm{MPa}$; this is consistent with the hardness measurements of the jacket before firing. Due to the face-centred cubic structure of this material and because it was heavily coldworked during the bullet's manufacture, strain-rate effects were assumed to be zero. To test this, we introduced a strain-rate sensitive term to the flow stress identical to the method used in [15] with a strain-rate constant equal to that of fully annealed copper. This resulted in very little change in the morphology of the penetrating bullet. The strain-to-failure values for this type of cold-worked alloy are typically less than 5 $\%$ [16] and therefore a principle strain failure criteria was used that was set to this value. However, we found that increasing the strain-to-failure to values as high as 30 $\%$ had little effect on the changing shape of the penetrating bullet and the depth-ofpenetration.

Modelling the failure of brittle materials is particularly troublesome not least because it is difficult to measure the strength of the comminuted material. A constitutive model presented by Johnson and Holmquist $[17,18]$ was used that had been previously calibrated for a $7.62 \mathrm{~mm} \times 51 \mathrm{~mm}$ NATO Ball round penetrating a glass laminate system by Richards et al [19]. The Johnson Holmquist damage model has been used previously by other researchers for these types of materials at a range of velocities [20,21] and is discussed in detail in previously presented work $[17,18,19]$. The polyurethane was modelled using a linear viscoelastic model summarised by the following recursive formula used to calculate the viscoelastic stresses [14]: 


$$
\sigma_{n+1}^{\prime}=\sigma_{n}^{\prime} e^{-\beta \Delta t}+2\left(G_{0}-G_{\infty}\right) \frac{\left(1-e^{-\beta \Delta t}\right)}{\beta} \dot{\varepsilon}^{\prime}
$$

Here, the long term behaviour of the material is described by the elastic shear modulus, $G_{\infty}$. Viscoelastic behaviour is modelled by the introduction of the instantaneous shear modulus, $G_{0}$ and a viscoelastic decay constant, $\beta$. $\Delta \mathrm{t}$ is the incremental time-step and $\dot{\varepsilon}^{\prime}$ is the strain-rate for that time-step.

Both the instantaneous shear modulus $G_{0}$ and the viscoelastic decay constant, $\beta$ were evaluated by simulating a rigid bullet passing through the resin without the glass and calibrating this value to the similar resin recovery rate and projectile residual velocity observed experimentally with the high speed video camera (689 \pm 10 $\mathrm{m} / \mathrm{s}$ for a beer-cup example). This yielded values of $G_{0}$ and $\beta$ of $119 \mathrm{MPa}$ and 21 respectively; $G_{\infty}$ was estimated from the elastic modulus measurements of $E$ (assuming $v=0.5$ ) and was $1.4 \mathrm{MPa}$. However due to $G_{0}>>G_{\infty}$, the modelling results were relatively insensitive to this value. Tensile failure of the resin was modelled by applying a principle failure strain of $150 \%$.

The equation of state was Mie-Grüneisen derived from a linear shock-particle relationship thus:

$$
U_{s}=c_{0}+S U_{p}
$$

where $U_{s}$ and $U_{p}$ are the shock and particle velocities respectively, $c_{0}$ is the bulk sound speed and $S$ is the slope in the $U_{s}$ versus $U_{p}$ diagram. Material data is available in the AUTODYN material libraries and is presented in Table 3. The AUTODYN material name is listed in brackets. 


\section{Table 3: NEAR HERE}

Table 4: NEAR HERE

Figure 2 shows a description of the numerical model set-up. The glass face of the target was modelled using a Smooth Particle Hydrodynamics (SPH) processor. This processor has previously been shown to be successful in modelling failure in brittle materials [22,23,24] due to the avoidance of erosion and ability to accommodate separation in the material due to cracking. It also has been used to model materials that are subjected to large deformations such as tungsten alloy penetrators [24] and polymer-based composites [25]. Consequently, the bullet core was modelled using SPH due to the very large amounts of deformation and material separation observed experimentally. The core consisted of 1550 SPH nodes. The glass targets consisted of 7750, 10250 and $12750 \mathrm{SPH}$ nodes for 6, 8 and 10-mm thick targets respectively. The jacket was modelled using a lagrangian jacket that provided good definition for this relatively thin $(0.75 \mathrm{~mm})$ complex shape and consisted of 505 cells. The resin was modelled using a lagrangian processor with an erosion strain of $200 \%$-- this was the minimum erosion strain tested that did not adversely affect the depth-of-penetration results. The mesh was graded at $15 \mathrm{~mm}$ from the central axis to expedite the simulations (see Figure 2). Each cell in the central zone was $0.4 \mathrm{~mm}$ in size. A lagrangian polycarbonate confinement was also added.

\section{Figure 2: NEAR HERE}

\section{RESULTS}

The depth-of-penetration results from the penetration into the targets of PRR are shown in Figure 3. The numerical results from the presented model set-up are also 
presented and demonstrate good correlation with the experimental measurements. An example of the penetration using $6 \mathrm{~mm}$ of glass facing is shown in Figure 4. For the beer-cup surround targets there was more scatter recorded in the penetration depths. The likely explanation for this is that due to the geometry and size of these targets, relatively little inertial confinement was offered to the penetrating projectile compared to the targets with the polycarbonate surrounds.

\section{Figure 3: NEAR HERE}

\section{Figure 4: NEAR HERE}

Figure 4 shows that during the penetration of the resin it has extended in length with the remnants being present along the whole length of the cavity. Measurements of the apparent diameter of the projectile showed that the expected reduction in diameter following the lengthening of the bullet, assuming constancy of volume in plastic deformation, had not occurred. Microscopy revealed extensive porosity along the length of the residual projectile. There was also evidence of mushrooming at the tip, as well as a series of broken petals and "wings" pointing in the direction of travel of the projectile. Typically, an amount of heavily distorted gilding metal from the jacket was present at the bottom of the cavity in the elastomer (See Figure 5). Smaller fragments of gilding metal can be seen along the length of the cavity.

\section{Figure 5: NEAR HERE}


This gilding metal has a similar hardness value as its original hardness which itself is typical of a cold-worked material with varying amounts of cold-work along the length of the bullet (see Table 1). Typical hardness measurements of the recovered gilding metal and the core material at the front of the penetrating mass are shown in Figure 6.

\section{Figure 6: NEAR HERE}

Analysis of the high speed video of a bullet penetrating the glass-faced system showed that as the round penetrates the PRR its tip is mushroomed into a hemispherical shape. The size of this shape was very much dependent on the thickness of the glass penetrated with the $10 \mathrm{~mm}$ glass face producing a hemispherical penetrating mass of approximately $20 \mathrm{~mm}$ diameter and the 6-mm glass face producing a hemispherical shape of $13 \mathrm{~mm}$ diameter. Material continues to flow from behind the projectile / target interface and when it encounters the PRR continues to mushroom. Typically for a 6-mm glass faced system between 50 and $75 \mu$ s after the mushroom begins to form, its radial expansion comes to a halt and elastic recovery of the PRR begins. The strain-energy that is stored in the resin by the radial expansion of the mushroom head is released and acts to contract the lead-antimony shank. The maximum diameter of the lead antimony shank is reached at $100 \mu$ s after contact between the bullet and the glass face. Post-mortem analysis of a projectile penetrating a glass-faced resin showed that the shank of the penetrating mass was contracted by $50 \%$ when compared to the early-in-time video measurements. Figure 7 shows the footage from the projectile penetrating a 6-mm faced target with the PRR cured into

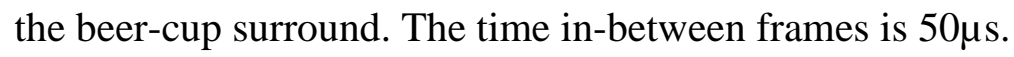




\section{Figure 7: NEAR HERE}

The numerical programme yielded some insights into the penetration mechanisms that footage from the high-speed video camera could not reveal. The penetration mechanism through the glass-face is typified by the 10-mm example shown in Figure 8 . At $10 \mu$ s after impact, the nose of the gilding jacket has been split and a process begins whereby the gilding metal is peeled away from the lead antimony core. Glass ahead of the penetrator is progressively damaged due to the accumulation of inelastic strains and is compressing the resin. Eventually, the strength of the damaged glass ahead of the penetrator forces the lead-antimony and the gilding metal to flow radially. By $40 \mu$ s the relatively soft lead antimony core was forced to flow in a mushroom-like fashion around the outside of the jacket. By $70 \mu$ s extensive deformation to the gilding metal has taken place as the core material appears to flow rearward with relation to the front of the penetrating mass. However, it still retains forward inertia. By $100 \mu \mathrm{s}$, the resin material forces the failed rear-flowing antimony material towards the axis of penetration.

\section{Figure 8: NEAR HERE}

\section{DISCUSSION}

The penetration of the $7.62 \mathrm{~mm} \times 51 \mathrm{~mm}$ NATO ball round into a glass-faced PPR resulted in an unusual penetration cavity. By comparing features of the penetrating mass at different time intervals we determined that the material on the outside of the penetrating mass was moving at a very much lower velocity than the centrally located material and in some cases appeared stationary. For example, with a 
6-mm case shown below in Figure 9 the lump indicated by ' $A$ ' at the top of the image is also present in a very similar location $25 \mu$ s later. Similarly the lumps contained within the oval ('B') appear to have not moved despite the penetration progressing. We believe that the most likely explanation for this is shown by the way in which the model predicted the penetration mechanism as shown in Figure 8. That is, during penetration core material is being forced from the central part of the penetrating mass to the extremities. Essentially, the bullet is being turned inside-out. Given that the front of the penetrating mass appears to a have a hemispherical shape - in the early stages at least, we believe this to be a reasonable assessment. This is similar to the fluid-jet penetration mechanisms seen with high velocity penetrators [26]. However, unlike the eroded debris from a fluid-jet penetrating a target (where the density of the jet is greater than the target) the lead antimony material that flows to the periphery appears to retain little or no inertia. This is probably due to the particulated penetrator material becoming embedded in the resin as a consequence of contact pressure (see Figure 10). Post-mortem analysis of the penetrated samples revealed that it was very difficult to separate the lead antimony core material that was embedded in the resin. Consequently, the final crater contained the deposits of lead antimony as shown in Figure 4.

\section{Figure 9: NEAR HERE}

\section{Figure 10: NEAR HERE}

Microhardness measurements of the gilding metal suggested that very little work-hardening had occurred and there was no evidence of re-crystallisation. The location of the gilding metal at the bottom of the crater as shown in Figure 5 suggests that the gilding metal is being stripped to offer the lead-antimony to the PRR but 
remains at the front of the penetration channel. This was also confirmed by the existence of an intact jacket after penetration of a 6-mm glass-faced target. In this case, it appeared that the front of the gilding jacket had been peeled back to offer the lead antimony material; the rear portion of the jacket remained intact (see Figure 11).

\section{Figure 11: NEAR HERE}

The simple viscoelastic model appeared to corroborate the main experimental observations in that the projectile's jacket was stripped away by the glass whilst the tail of the gilding metal came to rest at the bottom of the cavity. The gilding metal cells were mostly eroded during penetration whilst the material was being deposited along the length of the cavity. The modelling results also showed a hemisphericallyshaped penetrating mass moving into the resin. For the viscoelastic cases there was good agreement between the experimentally measured depth-of-penetration and the simulation results. However, the model was unable to simulate the apparent adhesion at the lead antimony / resin interface due to cell-erosion behind the penetrating mass and the resulting uneven penetration channel. Consequently the lead antimony that flowed rearward with respect to the penetration interface retained a forward velocity that was relatively small but significant compared to the penetration rate.

The modelling results showed that the penetration into glass led to the splitting of the gilding jacket and heavy deformation of the lead antimony core that eventually lead to a hemispherically-shaped plug of penetrating mass at the glass-PRR interface. The diameter of this penetrating mass that included the comminuted glass, the gilding metal and the lead antimony core material increased with the glass-face thickness and 
like the experiments varied from approximately $14 \mathrm{~mm}$ in diameter for the 6-mm case to $20 \mathrm{~mm}$ for the 10 -mm thick glass face.

The core within the cavity contained a significant amount of porosity. One explanation is that as the jacket is being stripped away, the lead antimony is particulated whilst being deposited. The recovery in the PRR then compresses the particulated lead-antimony to form a channel of relatively porous material. The formation of the "wings" along the core is unexplained but may be due to the turbulent flow of the lead-antimony as recovery occurs. Remnants of the leadantimony left on the recovered jacket shown in Figure 11 showed that it had flowed extensively however, no evidence of melting was found from the polished and etched sample. This indicated that the relatively low melting temperature of $\sim 250^{\circ} \mathrm{C}$ for this eutectic structure had not been reached at the latter stages of penetration. However, it is thought that the flow and / or particulation of the material would have been exacerbated by thermal softening. The measured hardness values for this material were comparable to the values quoted in Table 1 indicating that little hardening had occurred during penetration.

Finally, Figure 3 shows that increasing the thickness of glass results in a lower depth-of-penetration into the PRR resin. The weight advantage of each system can be assessed by comparing the areal densities of material penetrated, including the glass face and the resin. With this experimental set-up, the average areal density of material penetrated for the 6,8 and $10 \mathrm{~mm}$ glass-faced system was $103 \mathrm{~kg} / \mathrm{m}^{2}, 97 \mathrm{~kg} / \mathrm{m}^{2}$ and 90 $\mathrm{kg} / \mathrm{m}^{2}$ respectively (for the polycarbonate confined samples). Consequently, the 10 $\mathrm{mm}$ faced system is the most weight-efficient. This illustrates the importance of the glass face in deforming the projectile prior to penetrating the PRR resin. As the glass face thickness was increased, the degree of deformation in the lead antimony core was 
greater. Therefore, for this resin and this experimental set-up there is no weight advantage in using a larger resin thickness over glass.

\section{SUMMARY AND CONCLUSIONS}

The penetration of the lead antimony-cored $7.62 \mathrm{~mm} \times 51 \mathrm{~mm}$ bullet into a glass-faced polymer resin produces a rather unusual penetration cavity. The crater formed contained a porous bullet core with significant elongation. A simple linear viscoelastic model was applied to AUTODYN-2D to describe the behaviour of the resin and numerical results of the penetration morphology and depth-of-penetration appeared to match experimental observations well. Analysis of the high-speed camera footage and a numerical model of a bullet penetrating a viscoelastic polymer showed that during the initial stages of penetration, mushrooming and radial flow of the core material was occurring. Furthermore, it was evident from the experimental trials that contact between the porous lead antimony and the resin restricted the penetration. Experiments and numerical simulations both showed that the final shape of the cavity was defined by the relaxation of the polymer that leads to compression of the porous core material. A weight analysis of the penetrated materials showed that using a thicker tile of glass resulted in better ballistic performance.

\section{ACKNOWLEDGMENTS}

The authors would like to thank their Cranfield University colleagues: $\mathrm{Mr}$ Adrian Mustey for metallography and tensile testing, Mr Paul Moth for hardness testing and Mr Steven Champion and Mr David Miller for their assistance with the 
range facilities. Some of this work presented was carried out for Harvey Longstaff's Forensic Engineering and Science MSc project dissertation. The course chairman, Dr David Lane, is gratefully acknowledged.

\section{REFERENCES}

1. Edwards MR. Land-based military applications in "Comprehensive Composite Materials" volume 6 (M G Bader, K T Kedward and Y Sawada eds), Elsevier Science, Oxford, (2000), 681-99.

2. Radin J, Goldsmith W. Normal missile penetration and perforation of layered plates. Int. J. Impact Engng: 1988; 7: 229-259.

3. Wright SC, Fleck NA, Stronge WJ. Ballistic impact of polycarbonate-an experimental investigation. Int. J. of Impact Engng: 1993; 13 (1):1-20.

4. Bourne, NK. On the impact and penetration of soda-lime glass. Int. J. of Impact Engng: 2005; 32: 65-79.

5. Chaudhri MM, Kurkjian CR, Impact of small steel spheres on the surfaces of "normal” and "anamolous” glasses. Journal of the American Ceramic Society: 1986; 69 (5): 404-10.

6. Bouzid S, Nyoungue A, Azari Z, Bouaouadja N, Pluvinage G. Fracture criterion for glass under impact loading. Int. J. of Impact Engng: 2001; 25 (9): 831-845.

7. Wilkins M L, Honodel C A, Swale D, An Approach to the Study of Light Armour, Lawrence Radiation Laboratory, Livermore, UCRL-50284, June (1967).

8. Wilkins M L, Cline C F, Honodel C A, Fourth Progress Report of Light Armour Program, Lawrence Radiation Laboratory, Livermore, UCRL-50694 (1969). 
9. Wilkins M L, Landingham R L, Honodel C A, Fifth Progress Report of Light Armour Program, Lawrence Radiation Laboratory, Livermore, UCRL-50980, January (1971).

10. Hetherington J, The optimization of two component composite armours, Int. J. of Impact Engng: 1992; 12: 409-414.

11. Sadanandan S, Hetherington J G, Characterisation of ceramic/steel and ceramic/aluminium armours subjected to oblique impact. Int. J. of Impact Engng: 1997; 19: 811-819.

12. Hetherington J G, Rajagopalan B P, An investigation into the energy absorbed during ballistic perforation of composite armours. Int. J. of Impact Engng: 1991; 11: 33-40.

13. Chin S. Investigation of nanotechnology enhanced polyurethane replacement resin (PRR) as transparent armour material, MSc Thesis, Cranfield University, Shrivenham Campus, (2004).

14. AUTODYN ${ }^{T M}$ Theory Manual, Century Dynamics Limited, Dynamics House, Hurst Road, Horsham, West Sussex, RH12 2DT, UK.

15. Johnson GR, Cook WH. Fracture characteristics of three metals subjected to various strains, strain rates, temperatures and pressures. Engineering Fracture Mechanics: 1985; 21 (1): 31-48.

16. Properties and Selection: Nonferrous Alloys and Special-purpose Materials, Metals Handbook, Vol 2, $10^{\text {th }}$ Edition, ASM International (1990). 
17. Johnson GR, Holmquist TJ. An improved computational constitutive model for brittle materials, High Pressure Science and Technology_-1993, Part 2, American Institute of Physics, New York, pp. 981-984, (1994).

18. Holmquist TJ, Johnson GR, Grady DE, Lopatin CM, Hertel Jr. ES. High strain rate properties and constitutive modeling of glass, Proceedings of the 15th International Symposium on Ballistics, Jerusalem, Israel, Vol 1, 21-24 May 1995. p. 234-44.

19. Richards M, Clegg R, Howlett S. Ballistics performance assessment of glass laminates through experimental and numerical investigation. Proceedings of the 18th International Symposium on Ballistics, San Antonio, Texas, USA, Vol. 2, 15-19 November 1999, p. 1123-30.

20. McDonnell JAM, Catling DJ, Herbert MK, Clegg RA. Quasistatic to hypervelocity impactor loading of glass: Autodyn hydrocode and static testing configurations. Int. J. of Impact Engng: 2001; 26: 487-496.

21. Taylor EA, Tsembelis K, Hayhurst CJ, Kay L, Burchell MJ. Hydrocode modelling of hypervelocity impact on brittle materials: depth of penetration and conchoidal diameter. Int. J. of Impact Engng: 1999; 23: 895-904.

22. Clegg RA, Hayhurst CJ. Numerical modelling of the compressive and tensile response of brittle materials under high pressure dynamic loading. In Shock Compression of Condensed Matter - 1999 (M.D. Furnish, L. C. Chhabildas and R. S. Hixson), American Institute of Physics (2000), 321-324.

23. Lee M, Yoo YH. Analysis of ceramic/metal armour systems. Int. J. of Impact Engng: 2001; 25 (9): 819-29. 
24. Hayhurst CJ, Clegg RA, Livingstone IH, Francis NJ, The application of SPH techniques in AUTODYN-2D ${ }^{\mathrm{TM}}$ to Ballistic Impact Problems. In the proceedings of the $16^{\text {th }}$ International Symposium on Ballistics, San-Francisco, 23-28 September 1996

25. Quan X, Birnbaum N SPH simulation of the ballistic perforation of GFRP. In the proceedings of the $18^{\text {th }}$ International Symposium on Ballistics, 15-19 November 1999, San Antonio, Texas, USA.

26. Christman DR, Gehring JW. Analysis of high-velocity projectile penetration mechanics. J. Appl. Phys: 1966; 37 (4): 1579-87. 
Table 1: Key properties of the $7.62 \mathrm{~mm}$ NATO Ball round.

\begin{tabular}{|l|l|}
\hline Bullet mass & $9.4 \mathrm{~g}$ \\
\hline Core hardness HV (300 g load) & 10 \\
\hline Jacket hardness HV (300 g load) & $150-160$ (tip); $170-190$ (base) \\
\hline
\end{tabular}

Table 2: Measured mechanical properties of the resin.

\begin{tabular}{|l|l|}
\hline Density $\left(\mathrm{kg} / \mathrm{m}^{3}\right)$ & 1078 \\
\hline Hardness (Shore A) & 90 \\
\hline Tensile strength (MPa) & 16 \\
\hline Tensile elastic modulus (MPa) & 4.1 \\
\hline Elongation (\%) & $150-160$ \\
\hline Longitudinal wave velocity (km/s) & $1.94 \pm 0.04$ \\
\hline
\end{tabular}

Table 3: Hydrodynamic data for the materials used.

\begin{tabular}{|c|c|c|c|c|c|}
\cline { 2 - 5 } \multicolumn{1}{c|}{} & Notation & $\begin{array}{c}\text { PRR } \\
\text { (Polyrubber) }\end{array}$ & $\begin{array}{c}\text { Gilding metal } \\
\text { (Copper) }\end{array}$ & $\begin{array}{c}\text { Core } \\
\text { (Lead) }\end{array}$ & Polycarbonate \\
\hline $\begin{array}{c}\text { Reference density } \\
\left(\mathrm{kg} / \mathrm{m}^{3}\right)\end{array}$ & $\rho$ & 1010 & 8930 & 11340 & 1200 \\
\hline $\begin{array}{c}\text { Bulk sound speed } \\
(\mathrm{m} / \mathrm{s})\end{array}$ & $c_{0}$ & 852 & 3940 & 2006 & 2.65 \\
\hline $\begin{array}{c}\text { Slope in } U_{s} \text { versus } \\
U_{p} \text { diagram }\end{array}$ & $S$ & 1.865 & 1.489 & 1.429 & \\
\hline Grüneisen & $\Gamma$ & 1.50 & 2.02 & 2.74 & 0.61 \\
\hline coefficient & & & & & \\
\hline
\end{tabular}


Table 4: Strength data used for the materials.

\begin{tabular}{|c|c|c|c|c|}
\cline { 2 - 5 } \multicolumn{1}{c|}{} & Notation & Gilding metal & Core & Polycarbonate \\
\hline Shear modulus (GPa) & $G$ & 44 & 7 & 1 \\
\hline Yield stress (MPa) & $Y_{0}$ & 575 & 40 & - \\
\hline Thermal softening & $m$ & 1.09 & 1.0 & - \\
exponent & $T_{m}$ & 1323 & 525 & \\
\hline $\begin{array}{c}\text { Melting temperature } \\
\left({ }^{\circ} \mathrm{K}\right)\end{array}$ & & & & \\
\hline
\end{tabular}




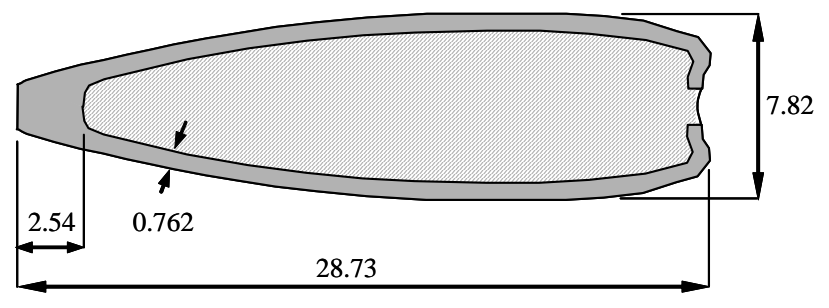

Figure 1: Geometry and key dimensions of the $7.62 \mathrm{~mm} \times 51 \mathrm{~mm}$ NATO ball bullet (dimensions in $\mathbf{m m})$.

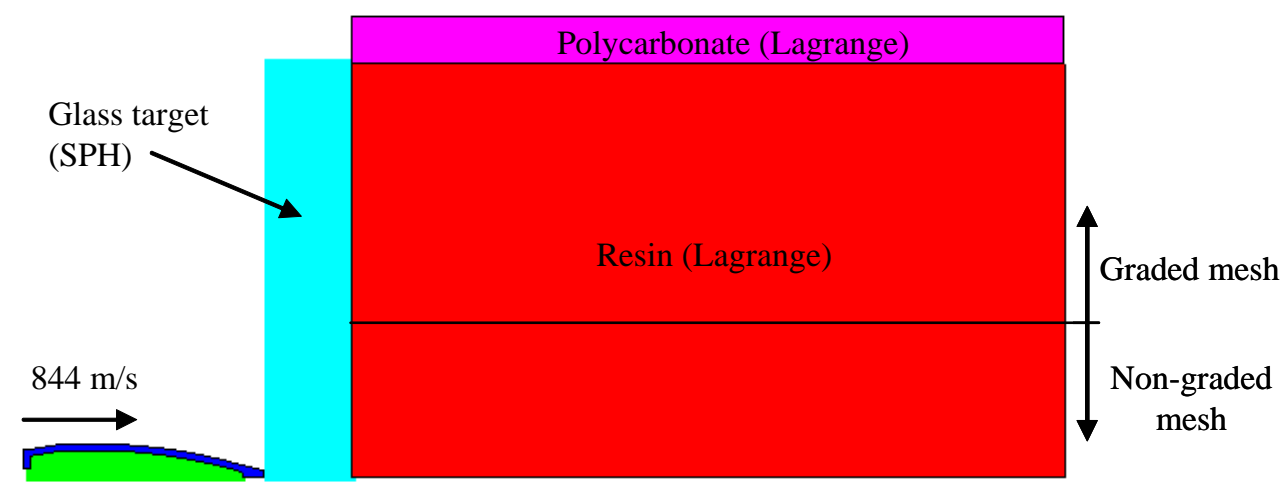

Figure 2: Numerical model set-up.

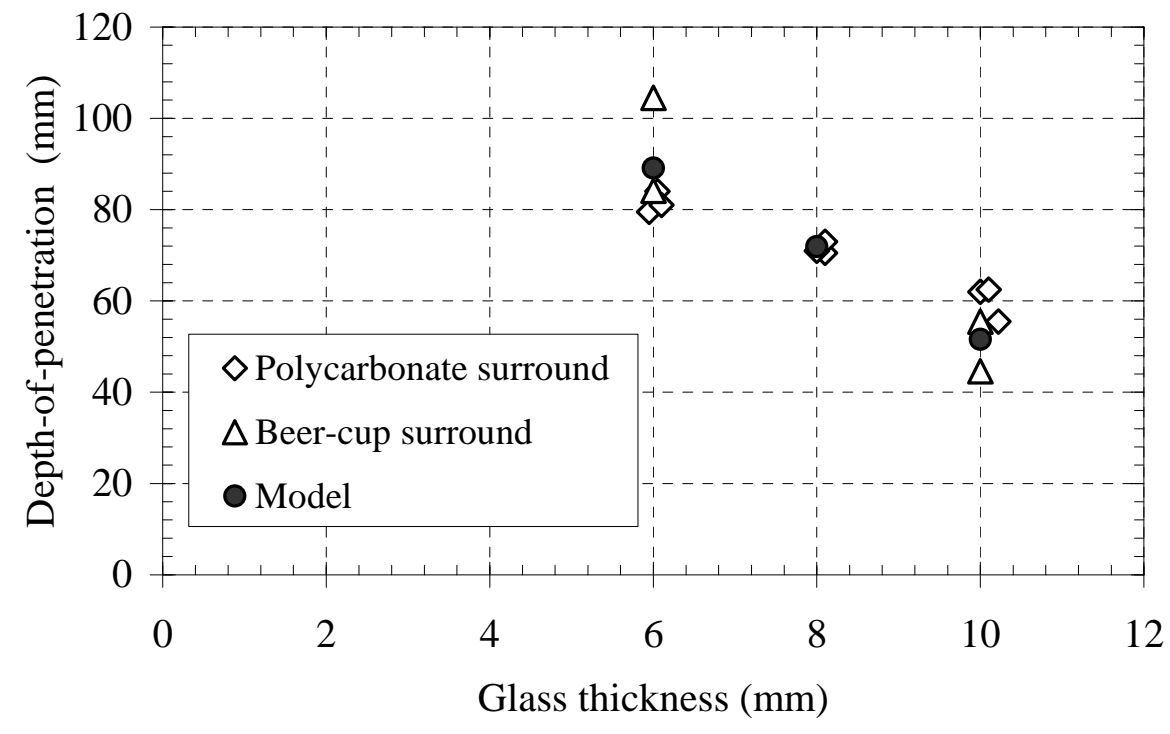

Figure 3: Depth-of-penetration (DOP) measurements. 


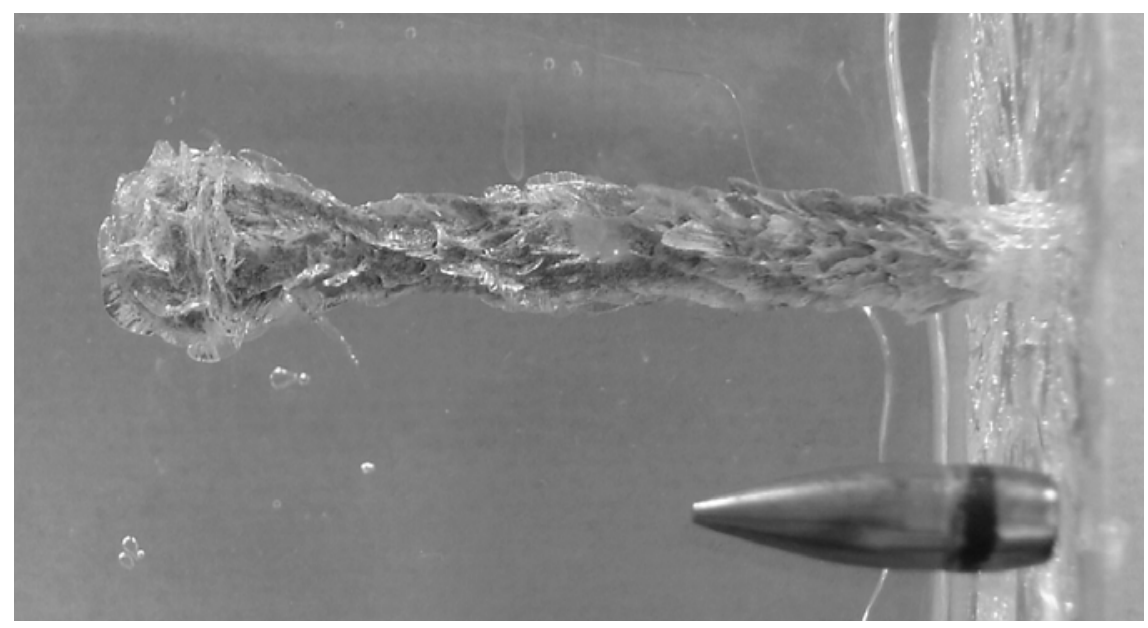

Figure 4: Penetrated 6-mm glass-faced target and 7.62 mm calibre bullet shown for comparison (polycarbonate surround).

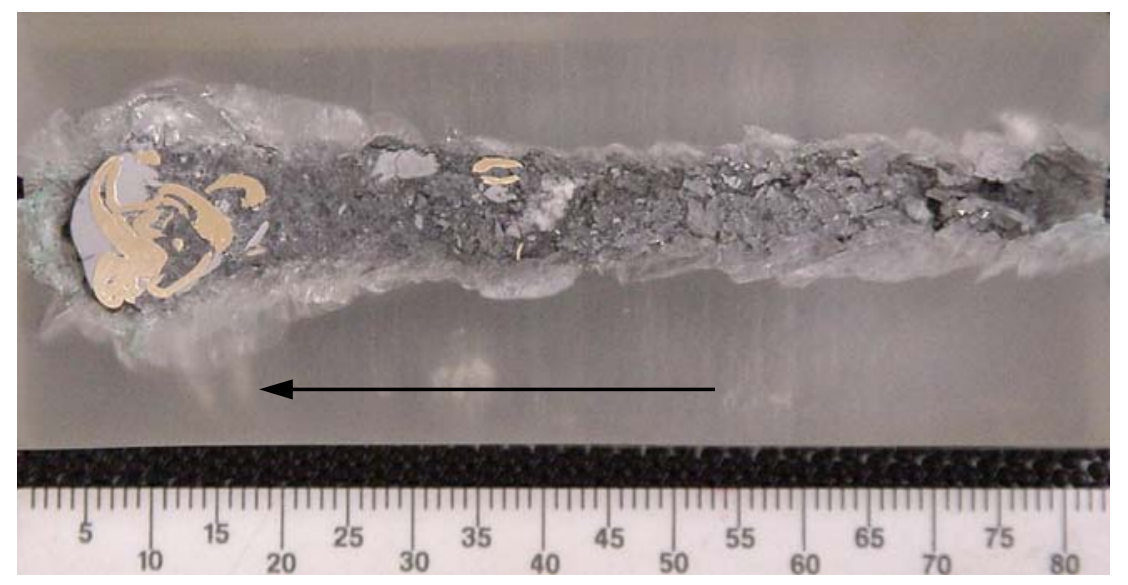

Figure 5: Cross-section of cavity showing glass, lead antimony and jacket after penetrating a 6-mm glass-faced resin target (beer-cup surround). The arrow shows the direction of penetration. 


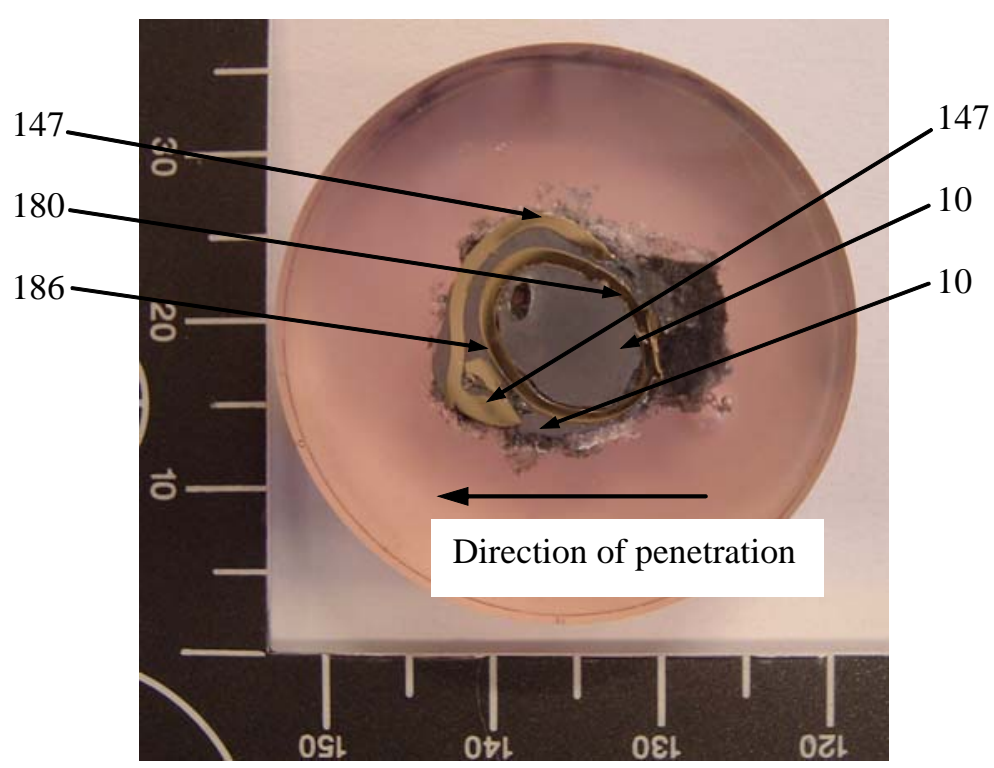

Figure 6: Vickers microhardness (100gF load) measurements of the gilding jacket and lead antimony at the head of the bullet remains after it has completely penetrated $6 \mathbf{~ m m}$ of glass and penetrated the PRR (polycarbonate surround).

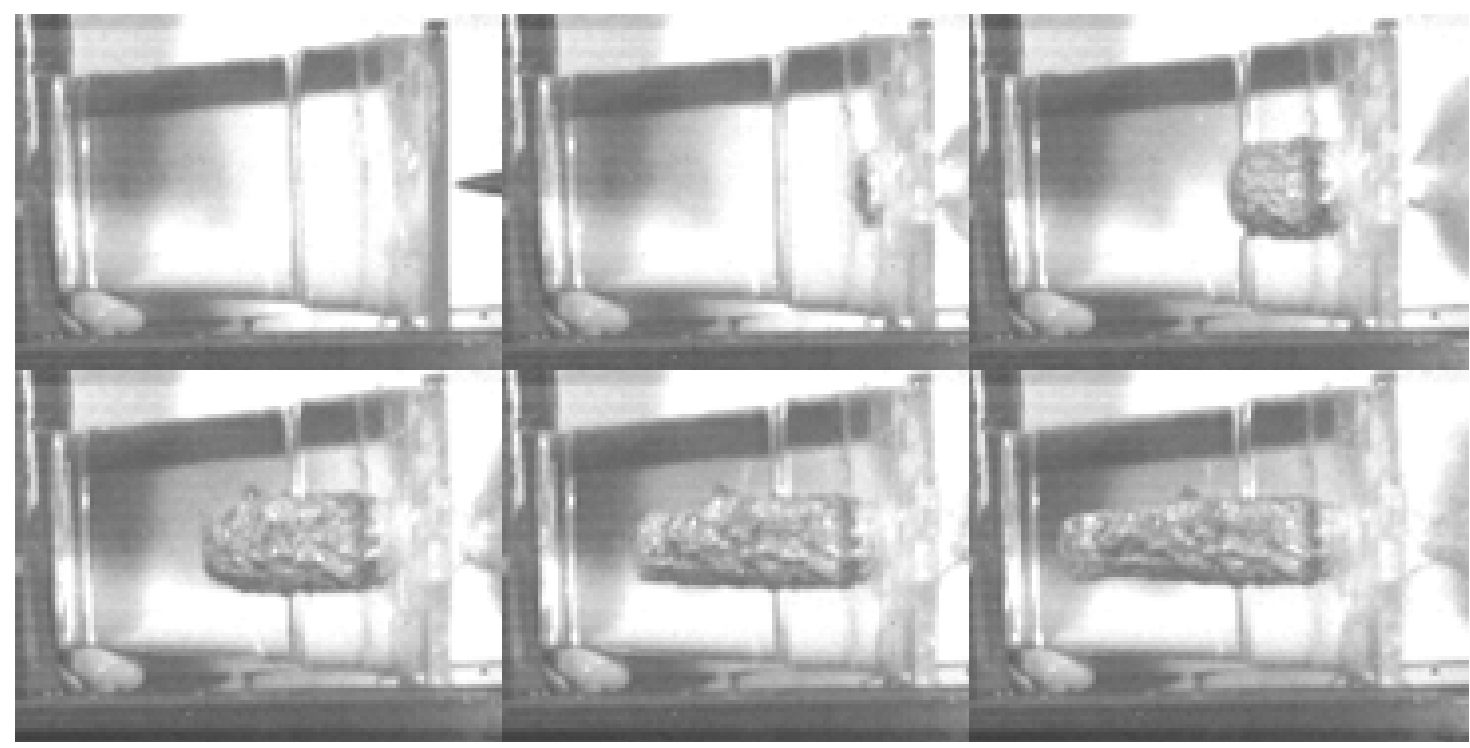

Figure 7: Penetration of a $7.62 \mathrm{~mm} \times 51 \mathrm{~mm}$ NATO Ball round into a 6-mm glass-faced PRR target (beer-cup surround); time between frames $=\mathbf{5 0} \mu \mathrm{s}$. The curved surfaces of the beer-cup produce a lens effect and consequently the penetrating mass appears larger in diameter than it actually is. 


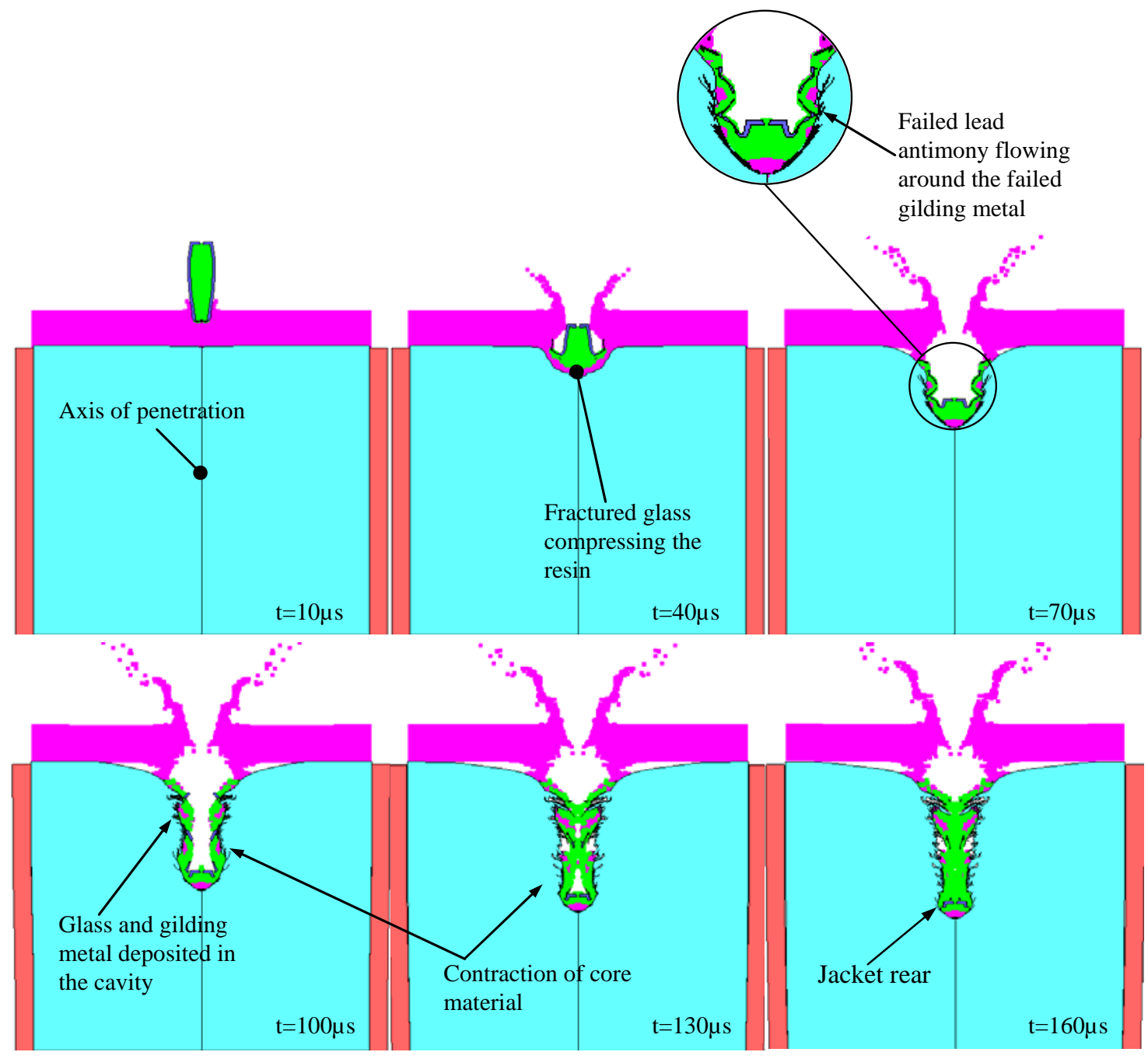

Figure 8: Numerical simulation of the penetration into a 10-mm glass-faced resin target with a polycarbonate surround; $t$ = time from impact of glass face. 


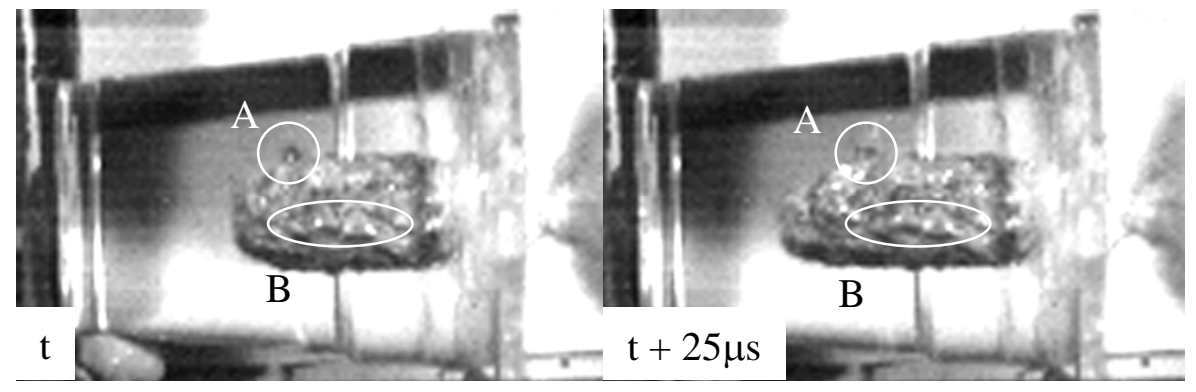

Figure 9: Penetration of a 6-mm glass-faced PRR target. The highlighted areas ' $A$ ' and ' $B$ ' indicate identical facets of the penetrating mass; time in-between frames is $25 \mu \mathrm{s}$.

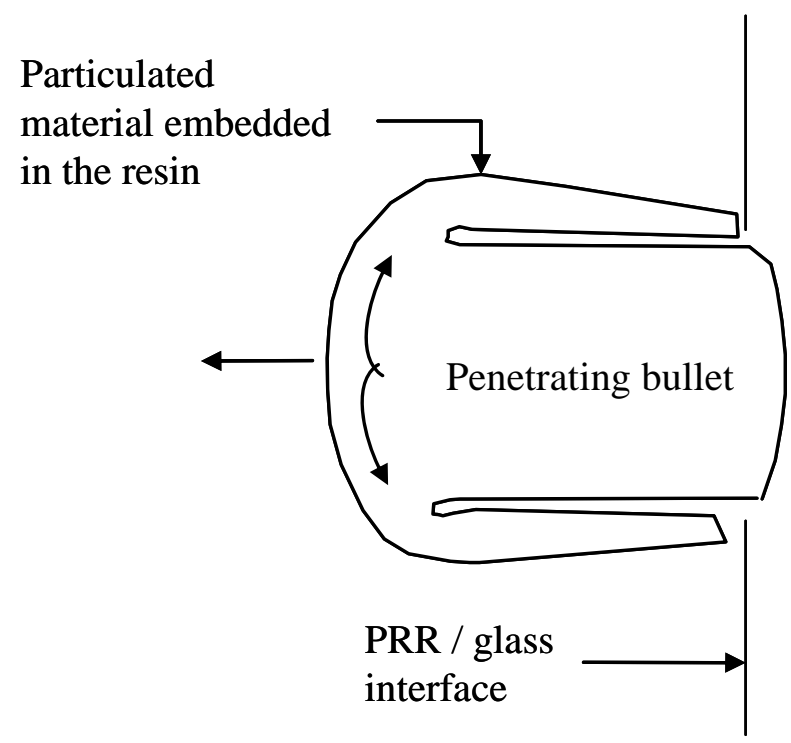

Figure 10: Penetration mechanism of the bullet. 


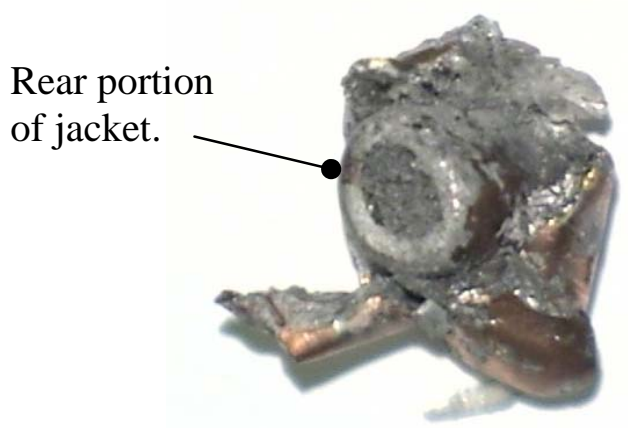

Figure 11: Recovered bullet after completely penetrating a 6-mm glass-faced PRR target (beer-cup surround). 